\title{
Examining Cross-Cultural Relationships Between Meaning in Life and Psychological Well-Being in Turkey and the United States
}

\author{
Ian C. Fischer, Ekin Secinti, Zeynep Cemalcilar \& Kevin L. Rand
}

\section{Introduction}

Empirical support demonstrating the benefits of meaning in life continues to emerge, with numerous studies documenting a robust relationship between meaning in life and overall well-being (Fischer, 2019). Several theories have been put forward to explain how meaning in life develops (e.g., Frankl, 1963; Ryff \& Singer, 1998; Wong, 2012; Schnell, 2010; Yalom, 1980) and numerous definitions have been generated (see Brandstatter et al., 2012, for a review). Despite these varied conceptualizations, however, consensus has begun to emerge that meaning in life refers to the perception that one's life is comprehensible, significant, and guided by important, valued goals (George \& Park, 2016; Heintzelman \& King 2014a; Martela \& Steger, 2016).

Possessing a high level of meaning in life appears to be an important contributor to mental and physical health across the lifespan (Cohen, Bavishi, \& Rozanski, 2016; Czekierda, Banik, Park, \& Luszczynska, 2017; Krause, 2007; Steger, Oishi, \& Kashdan, 2009; For discussions on how and why meaning in life is theorized to promote overall well-being, see: Goerge \& Park, 2016; McKnight \& Kashdan, 2009; and Steger, 2012). Individuals with higher levels of meaning in life tend to be happier and more satisfied with their lives (Peterson, Park, \&

\footnotetext{
${ }^{1}$ To date, research has focused primarily on the benefits of experiencing a sense of comprehensibility and purpose in life (George \& Park, 2014). However, significance, or the idea that one's life "matters" in the grand scheme, also contributes to a sense of meaning in life (e.g., Costin \& Vignoles, 2019; Schnell, 2009) and, recently, a new measure has been designed to address this gap (George \& Park, 2017).
}

This is the author's manuscript of the article published in final edited form as: 
Seligman, 2005; Steger, Frazier, Oishi, \& Kaler, 2006), experience less severe symptoms of anxiety and depression (Fahlman, Mercer, Gaskovski, Eastwood, \& Eastwood, 2009; Juhl \& Routledge, 2016; Kleftaras \& Psarra, 2012; Steger, Mann, Michels, \& Cooper, 2009; Winger, Adams, \& Mosher, 2016), use substances less (Schnetzer, Schulenberg, \& Buchanan, 2013), and live longer than those with lower levels of meaning (Boyle, Barnes, Buchman, \& Bennett, 2009).

\section{Presence and Search for Meaning}

Meaning in life is theorized to be comprised of two dimensions: presence of meaning and search for meaning (Steger et al., 2006). Presence refers to the extent to which individuals appraise their lives as having meaning (Steger et al., 2006). Search for meaning refers to the extent to which individuals are actively trying to develop meaning in life. Research does not always support the commonly-held belief that individuals only search for meaning when they feel without it; in fact, presence of meaning and search for meaning have been found to be unrelated (e.g., Steger et al., 2006). Some individuals search for meaning when they report having a high presence of meaning, and some individuals do not search for meaning even when they report a low presence of meaning; still others may search to find meaning for the first time (Dezutter et al., 2014). Accordingly, the process of searching for meaning is ambiguous, and myriad factors may contribute to its initiation. For example, individuals may search in an attempt to enhance existing levels of meaning or as a way to generate an additional kind (Steger et al., 2006; Steger, Kashdan, Sullivan, \& Lorentz, 2008). Alternatively, individuals may search as a way to rebuild a sense of meaning that has been threatened or eroded in some way. Schnell (2009) refers to this loss or reduction of meaning as a 'crisis' (p. 487) and notes that crises often prompt a search for meaning. 
Not surprisingly, because individuals search for meaning for different reasons, research examining the relationships between search for meaning and various aspects of psychological well-being has been mixed. In fact, search for meaning is often related to worse psychological well-being (e.g., depressive symptoms; Steger et al., 2006), but there is some evidence to suggest that it is also related to other characteristics generally considered to be positive (e.g., curiosity; Steger, Kashdan, et al., 2008). Thus, the motivations underlying individuals' search for meaning may influence how this search influences psychological well-being.

In line with this, there is evidence demonstrating that presence of meaning moderates the relationship between search for meaning and psychological well-being. For example, high levels of presence of meaning have been found to attenuate some of the distress that accompanies the search for meaning (Cohen \& Cairns, 2012; Park, Park, \& Peterson, 2010; Steger, Kawabata, Shimai, \& Otake, 2008; Steger, Mann, et al., 2009; Steger et al., 2011). Moreover, Cohen and Cairns (2012) found that individuals high in self-actualization (i.e., the desire to grow and enhance one's personal potential) were happiest when they were searching for meaning. Thus, those who already have meaning in life may engage in an active search as a way to augment, or deepen, existing sources, and this process may not be experienced as negative (Park et al., 2010). Conversely, those who search when they lack meaning may be engaging in a distressing effort to find meaning as a way to feel better (Frankl, 1985; Steger, Kashdan, et al., 2008). Indeed, several studies have demonstrated that individuals who experience a lack, or crisis, of meaning also experience high levels of psychological distress and low levels of positive psychological wellbeing (e.g., Damasio, Koller, \& Schnell, 2013; Pedersen et al., 2018; Schnell, Gerstner \& Krampe, 2018).

\section{Meaning in Life and Culture}


Motivations to search for meaning may also be influenced by culture (Steger, Kawabata, Shimai, \& Otake, 2008). Culture shapes goals, values, and expectations that can influence emotional experiences, life trajectories, and how individuals view themselves and their relationships to the wider world (Markus \& Kitayama, 1991; Singelis, Triandis, Bhawuk, \& Gelfand, 1995). Thus, culture may also influence how individuals develop, and experience, the presence of and search for meaning (Baumeister, 1991; Koltko-Rivera, 2004). To date, however, the majority of research on meaning in life has been conducted in Western (e.g., American) samples (Heintzelman \& King, 2014b), which precludes conclusions regarding how these dimensions are experienced across cultures. Indeed, limited research has examined meaning in life in non-Western cultures (Steger, Kawabata, et al., 2008), and the majority of this research has focused exclusively on the benefits of having meaning, neglecting the dynamic process of searching for meaning (e.g., Ho, Cheung, \& Cheung, 2010).

Existing research on presence of meaning in non-Western cultures, and cross-cultural comparisons between Western and non-Western samples, appears to indicate that possessing meaning may be universally adaptive (e.g., Dogra, Basu, \& Das, 2008; Pan, Wong, Joubert, \& Chan, 2008; Steger, Kawabata, et al., 2008). For example, Steger, Kawabata, and colleagues (2008) found the relationship between presence of meaning and happiness to be similar (i.e., positive) in Japanese and American college students. On the other hand, search for meaning may operate differently across cultures. In the same study, search for meaning was found to be negatively associated with happiness in the American sample, but unrelated to happiness in the Japanese sample. Moreover, presence and search were found to be positively associated in the Japanese sample, but negatively associated in the American sample, and presence of meaning was also found to moderate the relationship between search for meaning and happiness, but only 
in the American sample. These findings led the authors to suggest that cultural differences (i.e., individualism vs. collectivism), and resulting social and cognitive orientations (e.g., selfconstrual) may influence search for meaning, with individuals from collectivistic cultures experiencing a harmonious relationship between presence and search. In line with this idea, a positive relationship between presence and search was also found in a sample of Chinese college students (Wang \& Dai, 2008).

However, there is evidence to contradict the idea that purported differences between individualism and collectivism influence the relationship between presence and search. In other words, not all research utilizing collectivistic cultures has found a positive relationship between the presence of and search for meaning. For instance, this relationship has been found to be negative in studies in Turkey (Boyraz, Lightsey, \& Can, 2013) and in India (Singh, Junnarkar, Jaswal, \& Kaur, 2016). Like Japan, both Turkey and India are generally considered to embrace aspects of collectivism (Hofstede, 2001; Hofstede Insights, n.d.; House, Hanges, Javidan, Dorfman, \& Gupta, 2004). For example, Turkish culture emphasizes strong religious commitment and traditional values including, interrelatedness and close ties with family members and friends (Ahmadi, Erbil, Ahmadi, \& Cetrez, 2019; Imamoglu \& Imamoglu, 1992; Imamoglu, Kuller, Imamoglu, \& Kuller, 1993). Thus, these mixed findings suggest that there may be differences between broadly collectivistic cultures, as well as factors that transcend culture, that have relevance for the relationship between the presence of and search for meaning in life.

For example, certain developmental processes, such as those seen within the stage of emerging adulthood (Arnett, 2000; Atak \& Çok, 2008), may play a influential role in the development and pursuit of meaning in life. During this stage, the exploration of personality 
identity is predominant, and the search for meaning in life is common (Arnett, 2000; Steger, Oishi, \& Kashdan, 2009). Thus, although cultural differences such as individualism and collectivism may begin to explain the differential relationships seen across certain cultures regarding the relationship between presence and search (Steger, Kawabata, et al., 2008), the explanatory power of this hypothesis may vary depending on the cultures tested and the developmental stage of the participants assessed. Indeed, younger individuals, regardless of culture, tend to hold more individualistic values (Fung et al., 2016; Greenfield, 2014). Thus, broad cultural differences may have less influence on the ways in which the presence of and search for meaning relate to psychological well-being than has been previously stated.

Consequently, further research is needed to clarify how the presence and search for meaning are experienced across cultures, including how they relate to each other and whether they interact to predict psychological well-being.

To our knowledge, Steger, Kawabata, and colleagues' (2008) study is one of the first cross-cultural examinations of the presence and search for meaning in life, and the only to assess for the potential interaction between these two dimensions when predicting psychological wellbeing. Moreover, because they only examined one aspect of psychological well-being (i.e., happiness), it is not clear whether the results hold for other aspects of well-being, including negative aspects. Psychological well-being is multidimensional and encompasses both positive and negative aspects that do not exist on a continuum (Kern, Waters, Adler, \& White, 2015; Watson, Clark, \& Tellegen, 1988); presence and search may interact differently across cultures when predicting these particular kinds of well-being.

Thus, additional research is needed to contextualize and clarify how the presence and search for meaning relate across cultures. It remains an open question whether the interaction 
between presence and search occurs exclusively in societies generally considered to be individualistic (e.g., the United States; Steger et al., 2008) and with regard to positive psychological well-being, or if it generalizes to other societies generally considered to be collectivistic and with regard to negative aspects of well-being as well (e.g., anxiety). Addressing these questions may provide preliminary evidence for the generalizability of these processes across certain cultures (i.e., individualistic and collectivistic), or it may illuminate important differences.

\section{The Current Study}

The purpose of the current study was to examine the relationships between the presence of and search for meaning in life and different aspects of positive (i.e., satisfaction with life) and negative (i.e., anxiety and depressive symptoms) psychological well-being in groups of college students from the United States and Turkey. We chose these two samples because they exist within societies considered to be individualistic and collectivistic, respectively (Hofstede, 2001). Accordingly, cultural values of the broader society should be present within these individuals to a certain degree, if not entirely.

We aimed to examine the associations between presence and search in each country, as well as how these variables relate to different aspects of psychological well-being, and whether the strength of these relationships differed as a function of larger cultural contexts. Based on existing research (Boyraz, Lightsey, et al., 2013; Steger et al., 2006), we expected that there would be a negative relationship between presence and search in both the American and Turkish samples (Hypothesis 1). Also based on existing research (Dogan, Sapmaz, Tel, Sapmaz, \& Temizel; Steger et al., 2006), we hypothesized that greater presence of meaning would be similarly associated with all indices of well-being in both samples (i.e., greater satisfaction with 
life and lower anxiety and depressive symptoms) (Hypothesis 2), and that greater search for meaning would be negatively associated with life satisfaction and positively associated with depressive symptoms and anxiety in both samples (Hypothesis 3). Considering these bivariate hypotheses and the similar demographics of our two samples (i.e., college-aged individuals), we also hypothesized that the presence and search for meaning would interact similarly in the two samples, despite the presence of broad cultural differences. Specifically, we hypothesized that there would be a significant interaction between presence and search for meaning within each sample, such that presence of meaning would buffer the negative effects of search for meaning on psychological well-being and amplify the positive effects.

\section{Method}

\section{Sample and Procedure}

Data were collected from undergraduate psychology students in two countries using online subject pools: US and Turkey. In both settings, participants anonymously completed online surveys in exchange for course credit after providing informed consent. Study protocols were approved by the Institutional Review Boards of Indiana Univeristy Purdue University at Indianapolis (IUPUI) and Koc University.

\section{United States sample}

A total of 377 (87\% female) participants were recruited from a large, urban university in the Midwestern United States. The average age of participants was 19.3 years $(\mathrm{SD}=3.4)$. Participants were mostly Caucasian (74\%), with the remaining identifying as African American (11\%), Asian American (7\%) Latinx (3\%), Multiracial (2\%), and Native American $(<1 \%)$.

\section{Turkish sample}


A total of 225 participants ( $80 \%$ female) were recruited from an urban university in Western Turkey. The average age of participants was 20.4 years $(\mathrm{SD}=1.8)$. All participants identified as Turkish.

Measures

All participants completed a self-report demographic questionnaire and the validated selfreport measures listed below. For all measures, higher scores indicate greater levels of symptoms/outcomes. Internal consistency reliabilities of all measures are presented in Table 1. Meaning in Life

Meaning in life was assessed using the English and Turkish versions of the 10-item Meaning in Life Questionnaire (MLQ; Boyraz, Lightsey, et al., 2013; Steger et al., 2006). Five items assess presence of meaning in life (e.g., "I have a good sense of what makes my life meaningful") and five items assess search for meaning in life (e.g., "I am always looking to find my life's purpose"). Responses are rated on a 7-point Likert-type scale ( 1 = Absolutely untrue to $7=$ Absolutely true). Both the English and Turkish versions of the MLQ have been shown to be reliable and valid (Boyraz, Lightsey, et al., 2013; Steger et al., 2006).

\section{Satisfaction with Life}

Satisfaction with life was assessed using the English and Turkish versions of the 5-item Satisfaction with Life Scale (SWLS; Diener, Emmons, Larsen, \& Griffin, 1985; Köker, 1991). All items assess satisfaction with life in general (e.g. "I am satisfied with my life") and are rated on a 7-point Likert-type scale $(1=$ Strongly disagree to $7=$ Strongly agree $)$. Both the English and Turkish versions of the SWLS have been shown to be reliable and valid (Dagli \& Baysal, 2016; Diener et al., 1985; Köker, 1991).

Anxiety 
Anxiety was assessed using the English and Turkish versions of the 20-item State Trait Anxiety Inventory - State Anxiety subscale (STAI-S; Spielberger, Gorsuch, Lushene, Vagg, \& Jacobs, 1983; Öner \& Le Compte, 1983). All items assessed how participants are currently feeling (e.g., "I am tense"). Items are rated on a 4-point Likert-type scale $(1=$ Not at All to $4=$ Very Much So). Both the English and Turkish versions of the STAI-S have been shown to be reliable and valid (Spielberger et al., 1983; Öner \& Le Compte, 1983).

Depressive symptoms

In the US sample, depressive symptoms were assessed using the 20 -item Center for Epidemiological Studies-Depression scale (e.g., "I had trouble keeping my mind on what I was doing") (CES-D; Radloff, 1977). Responses are rated on a 4-point Likert-type scale (0 = Rarely or none of the time to $3=$ Most or all the time). The CES-D has been shown to be reliable and valid (Radloff, 1977). In the Turkish sample, depressive symptoms were assessed using the Turkish version of the 21-item Beck Depression Inventory-II (e.g., "I am less interested in other people or things than before") (BDI-II; Kapci, Uslu, Turkcapar, \& Karaoglan, 2008). Each item on the BDI-II has an ordered-response format that ranges in severity (e.g., $0=$ I do not feel sad to 3 = I am so sad or unhappy I can't stand it). The BDI-II is one of the most widely used measures of depressive symptoms in Turkey and the Turkish version has been shown to be reliable and valid (Kapci et al., 2008). To use a common metric, CES-D scores were transformed into BDI-II equivalent scores using established transformations (Gonzalez \& Jenkins, 2014). ${ }^{2}$

Data analysis

\footnotetext{
${ }^{2}$ Because part of this data was collected for a larger study, we had different measures of depressive symptoms in the samples. CES-D scale scores were converted into BDI-II scores using conversion formulas developed by Gonzales \& Jenkins (2014). As a sensitivity analysis, we also transformed BDI-II scores into CES-D equivalent scores and reran moderation analyses. Findings were highly similar in both sets of analyses. Results are reported in BDI-II metric.
} 
Participants with significant missing data were excluded from analyses (i.e., less than one measure of complete data; $n=16$ in the US sample and $n=23$ in the Turkish sample) and outliers were winsorized to 3 SDs (Tukey, 1962). To examine whether the strength of the relationships between meaning in life and psychological well-being variables differed across cultures we conducted moderation analyses. Moderation analyses focused on whether culture (dummy coded as Turkey $=-1$ and US $=1$ ) moderated the relationship between search for meaning and presence of meaning (Hypothesis 1), or presence of meaning and psychological well-being (Hypothesis 2) or search for meaning and psychological well-being (Hypothesis 3), controlling for age and gender (dummy coded as male $=-1$, female $=1$ ). Finally, to determine whether the relationship between search for meaning and psychological well-being was differentially influenced by presence of meaning across cultures, we ran moderated moderation analyses that produced three-way interactions (Hypothesis 4). All analyses were run using SPSS version 25 and the PROCESS macro version 2 (Hayes, 2013).

\section{Results}

\section{Preliminary Analyses}

Table 1 presents descriptive statistics and bivariate correlations. The Turkish sample was significantly older (20.4 years vs. 19.3 years), $t(562)=4.44, p<.0001$ and included a larger percentage of male participants $(20.1 \%$ vs. $13.0 \%), \chi^{2}(1, N=564)=5.03, p=.025$ than the US sample. Regarding psychological variables, no significant differences were found between groups.

Bivariate analyses indicated that presence of meaning was correlated in the expected directions with all indices of well-being in both groups, and search for meaning was positively associated with anxiety and depressive symptoms in both groups (See Table 1). In partial support 
of our hypothesis, search for meaning was negatively associated with satisfaction with life $(r=-$ $.30, p<.001)$, but only in the Turkish sample.

\section{Moderation analyses}

Simple moderation analyses indicated that there was no significant interaction between search for meaning and culture when predicting presence of meaning, controlling for age and gender $(b=.04, p=.394)$. Thus, consistent with our first hypothesis, in both the US and Turkish samples, search for meaning was negatively associated with presence of meaning $(r=-.14$ and .20 , respectively, See Table 1).

Consistent with our second hypothesis, we found that culture was not a significant moderator of the relationships between presence of meaning and satisfaction in life $(b=.03, p=$ $.413)$, anxiety $(b=-.10, p=.170)$ or depressive symptoms $(b=.06, p=.173)$. In addition, in partial support of our third hypothesis, culture was not a significant moderator of the relationships between search for meaning and anxiety $(b=-.07, p=.383)$ or search for meaning and depressive symptoms $(b=-.10, p=.059)$. However, culture was a significant moderator of the relationship between search for meaning and satisfaction with life $(b=.11, p=.007$; see Table 2). Simple slopes analysis revealed a significant negative relationship between search for meaning and satisfaction with life in the Turkish sample $(b=-.31)$, and a non-significant relationship in the US sample $(b=-.08$; See Figure 1).

To test our fourth hypothesis, we examined the interactions between search for meaning, presence of meaning, and culture in predicting psychological well-being outcomes. The results indicated significant interactions when predicting depressive symptoms $(b=.02, p=.015)$ and anxiety $(b=.03, p=.002$; see Table 3$)$. We graphed the relationships between search for meaning and anxiety and search for meaning and depressive symptoms at low (1 SD below) and 
high (1 SD above) levels of the presence of meaning in each sample (See Figure 2). As can be seen, our hypothesis was partially supported. Presence of meaning appears to have a buffering effect, but in the Turkish sample only; specifically, as presence of meaning increases, the relationships between search for meaning and anxiety and search for meaning and depressive symptoms weaken. Conversely, in the US sample, this buffering effect does not seem to occur. In addition, in contrast to what we predicted, no significant three-way interaction was found when predicting satisfaction with life $(b=-.01, p=.171)$.

\section{Discussion}

To date, few studies have investigated how different dimensions of meaning in life (i.e., presence of meaning and search for meaning) operate across cultures. In the current study, we analyzed these dimensions in samples of American and Turkish college students, examining how they related across groups, whether they similarly predicted psychological well-being, and if presence of meaning moderated the relationships between search for meaning and aspects of psychological well-being. Overall, the results partially supported our hypotheses. Presence of meaning was consistently associated with better psychological well-being across groups, while search for meaning was generally related to worse psychological well-being. In some cases, the relationship between search for meaning and psychological well-being was moderated by presence of meaning, although not always in the expected direction. Our results suggest that presence of meaning may have similar benefits across cultures, while search for meaning may have culturally-specific aspects that produce differential effects on psychological well-being. We discuss the implications of these findings below.

In both American and Turkish students, we found that lower presence of meaning was associated with greater search for meaning. While these relationships were not particularly 
strong, the results line up with previous research in these populations (Boyraz, Lightsey Jr, \& Can, 2013; Steger et al., 2006) and suggest that both groups tend to engage in a process of searching for meaning when presence of meaning is appraised as low. One interpretation of these findings is that both groups view the development of meaning in life as a way to alleviate symptoms of psychological distress (e.g., depressive symptoms) and improve well-being (e.g., satisfaction with life). In other words, the development of meaning in life may be seen as a mechanism that enhances quality of life. Another interpretation is that both groups search for meaning, in part, because it is developmentally appropriate. Indeed, during the college years, individuals are trying to make sense of themselves, their lives, and how best to operate within the wider world (Arnett, 2000). This period of "emerging adulthood" is predominated by the exploration of personal identity and often includes the search for meaning in life (Arnett, 2000). As such, the negative relationship between presence and search in the current samples may not indicate that personal meaning is viewed as a pathway to greater overall well-being per se; rather, individuals may search for meaning as a way to enrich personal understanding and expand their sense of self, and increases in well-being may be a byproduct of this developmental process.

Considering that existing cross-cultural research on meaning in life has supported a positive relationship between presence and search in other, traditionally collectivistic societies (Steger, Kawabata, et al., 2008; Wang \& Dai, 2008), one interpretation of our results is that there are differences between broadly collectivist societies. For instance, as discussed by Steger, Kawabata, and colleagues (2008), collectivism within East Asian cultures may be characterized by preferences for interconnection and harmony, as well as a greater tolerance for contradiction and impermanence which can, in fact, be found in many Eastern philosophies (e.g., Taoism). 
Thus, presence of meaning may be viewed as ephemeral and in need of constant development, which could explain the positive relationship. By contrast, in Turkish culture, which is also considered collectivistic but influenced by both European and Middle Eastern cultures, presence of meaning may be conceptualized as stable and constant (i.e., something that does not typically require maintenance). This viewpoint would be consistent with the teachings of various monotheistic religions (e.g., Christianity), which outline particular pathways that promote a meaningful life (e.g., zakat in Islam), and in line with existing research demonstrating that the presence of meaning partially mediates the relationship between religiousness and psychological well-being (Krok, 2014, 2015). Individuals may not feel the need to continue to search for meaning if they view themselves as acting appropriately and in accordance with doctrine. This interpretation would be in line with existing research demonstrating that meaning in life is a mediator of the relationship between

Alternatively, our results may have emerged because our Turkish sample was predominantly individualistic. There is some evidence indicating that Turkish students tend to be more individualistic than other members of Turkish society (Karakitapoĝlu-Aygün \& Imamoĝlu, 2002), and American and Turkish students might have similar levels of individualism (autonomy; Cukur et al., 2004). Both American and Turkish students may be focused on the advancement of self-esteem or engaged in efforts to distinguish themselves from the group (Triandis \& Gelfand, 1998), and these efforts may produce a sense of meaning in life.

Broadly, our results suggest that all individuals, regardless of culture, benefit psychologically from possessing a sense of meaning in life. Indeed, in both cultures, higher presence of meaning was associated with better psychological well-being. This fits with the constructivist nature of meaning in life (Klinger, 1977), which suggests that meaning is unique to 
each individual. Accordingly, culture is less likely to affect the level of meaning in life seen across groups; rather, if anything, culture should influence the sources from which individuals turn to develop meaning. For example, the appraisal that one's life is guided by important, valued goals (i.e., purpose in life) could come from advancements of self (e.g., pursuing one's career) or it could develop from the advancement of one's group (e.g., caring for one's family).

The current study also demonstrated that there may be differences regarding how search for meaning relates to psychological well-being across groups. Indeed, at the bivariate level, while search for meaning was associated with anxiety and depressive symptoms in both groups, it was more strongly related to these outcomes in the Turkish sample. This stronger relationship to distress may reflect the discomfort that can develop when going against the broader views of society. If Turkish students are more individualistic than many of the influential persons in their lives (e.g., parents), efforts to develop meaning in life, which could manifest as efforts that promote the self over the group, may produce symptoms of anxiety and distress when they clash with traditional values (e.g., obedience; Kagitcibasi, 2005). At the same time, our results also suggest that Turkish students, in particular, may be protected from the negative effects associated with the search for meaning; indeed, high levels of presence of meaning were found to attenuate symptoms of anxiety and depression, but only in the Turkish sample. These differences may be explained by the motivations that underlie individuals' search for meaning.

In the current sample, Turkish students may have been more focused on strengthening existing sources of meaning (e.g., familial relationships, religious faith; Emmons, 2003; Reker \& Woo, 2011; Schnell, 2011), and less interested in pursuing new ones. Indeed, within collectivistic societies that prioritize the group over the individual, the search for meaning may 
manifest in activities that enhance unity and social cohesion. ${ }^{3}$ If true, the awareness that one has already been successful in this regard (high presence of meaning) may reduce a sense of urgency and uncertainty. Nevertheless, this process may not lead to increased satisfaction with life. Indeed, for Turkish students, search for meaning was negatively associated with this outcome, regardless of individuals' level of presence of meaning. This may be because existing sources of meaning do not always line up with personal preferences or values. For example, further cultivation of one's familial relationships may lead to increases in meaning in life but not overall satisfaction with life.

American students, on the other hand, may have been devoting their efforts toward developing alternative sources of meaning. In fact, our results suggest that American students experienced a heightened sense of discomfort in cases where they were searching for meaning and already had high levels of presence of meaning. These individuals may be beginning to question existing sources of meaning that may have been provided by others (e.g., peer groups, social media) and starting to pursue other, more intrinsic sources in their place. This process may create distress and reduce well-being, at least in the short-term. Alternatively, American college students may have been searching to establish additional sources of meaning in life, and this uncertain process may not be assuaged by the presence of a particular kind of meaning already established. That is, existing sources of meaning (e.g., athletic prowess) may not assist the development of a new kind (e.g., close friendships), or reduce the distress that accompanies this process. Indeed, college is a time of self-development and perceived temporal abundance

\footnotetext{
${ }^{3}$ This may be especially true in collectivistic societies that are also considered to be tight (i.e., societies that have clear social norms and limited tolerance of deviance from those norms). Turkey is considered to be tighter than the United States (Uz, 2014), and this difference may have implications for how the process of searching for meaning unfolds within these two countries. However, because we did not collect any data that would allow us to examine the reasons why our samples were actively searching for meaning, this question cannot be addressed and awaits future research.
} 
(Carstensen, 2006), and students may be trying to cultivate various roles and goals as a way to further their knowledge of self and the world.

\section{Limitations and Future Directions}

Study limitations and potential directions for future research are worth noting. First, due to the cross-sectional nature of the study, causality cannot be assessed. Future longitudinal studies are necessary to clarify the directionality of these associations. Additionally, our samples consisted of undergraduate students, the majority of which were women. Future cross-cultural research with diverse samples is required to clarify the generalizability of our findings. Moreover, because different measures of depressive symptoms were used, potential measurement effects need to be considered. However, based on prior research, we used an accepted approach to transform depression scores to compare findings across two cultures (Gonzales \& Jenkins, 2014). In the future, culture should be assessed directly to examine the extent to which samples collected in different countries align with individualistic/collectivistic values. In addition, future qualitative studies would help to untangle how individuals conceptualize the goal of meaning in life. Particular factors (e.g., presence of meaning) may better assist certain searches for meaning that may be culturally influenced. Finally, it will be useful to examine how dimensions of meaning in life vary within cultures, and how particular values that undergird the decision to engage in a process of searching for meaning (e.g., selfdevelopment) may be facilitated or hindered by broader sociocultural dynamics.

\section{Conclusion}

Overall, the results of the current study demonstrate that meaning in life is an important contributor to psychological well-being. In particular, our findings suggest that, while high levels of presence of meaning may have benefits that transcend culture, search for meaning may have 
unique relationships with psychological well-being that depend, at least in part, on factors that are culturally influenced. Future research should continue to explore how, and under what conditions, search for meaning becomes more or less adaptive. Indeed, while the process of developing meaning in one's life is intricate and undoubtedly personal, it is also influenced by the environment and those in it. An understanding of how cultural phenomena influences meaning in life in general, and the search for meaning in particular, is just beginning and continued research is necessary.

\section{Compliance with Ethical Standards}

\section{Disclosure of potential conflicts of interest}

The authors have no conflicts of interest to disclose.

\section{Ethical approval}

All procedures performed in studies involving human participants were in accordance with the ethical standards of the institutional and/or national research committee and with the 1964 Helsinki declaration and its later amendments or comparable ethical standards.

\section{Informed consent}

Informed consent was obtained from all individual participants included in the study. 


\section{References}

Ahmadi, F., Erbil, P., Ahmadi, N., \& Cetrez, O. A., (2019). Religion, culture and meaningmaking coping: A study among cancer patients in Turkey. Journal of Religion and Health, 58, 1115-1124. https://doi.org/10.1007/s10943-018-0646-7

Arnett, J. J. (2000). Emerging adulthood: A theory of development from the late teens through the twenties. American psychologist, 55, 469-480.

Atak, H., \& Çok, F. (2008). The Turkish version of inventory of the dimensions of emerging adulthood (The IDEA). International Journal of Humanities and Social Sciences, 3, 148154.

Battista, J., \& Almond, R. (1973). The development of meaning in life. Psychiatry: Journal for the Study of Interpersonal Processes, 36(4), 409-427.

Baumeister, R. F. (1991). Meanings of life: Guilford Press.

Boyle, P. A., Barnes, L. L., Buchman, A. S., \& Bennett, D. A. (2009). Purpose in life is associated with mortality among community-dwelling older persons. Psychosomatic medicine, 71, 574-579.

Boyraz, G., Lightsey Jr, O. R., \& Can, A. (2013). The Turkish version of the Meaning in Life Questionnaire: assessing the measurement invariance across Turkish and American adult samples. Journal of Personality Assessment, 95, 423-431.

Brandstätter, M., Baumann, U., Borasio, G. D., \& Fegg, M. J. (2012). Systematic review of meaning in life assessment instruments. Psycho-Oncology, 21(10), 1034-1052.

Breitbart, W., Rosenfeld, B., Gibson, C., Pessin, H., Poppito, S., Nelson, C., ... \& Sorger, B. (2010). Meaning-centered group psychotherapy for patients with advanced cancer: a pilot randomized controlled trial. Psycho-Oncology, 19(1), 21-28. 
Camus, A. (1965). The myth of Sisyphus, and other essays. London: H. Hamilton.

Carstensen, L. L. (2006). The influence of a sense of time on human development. Science, 312, 1913-1915.

Cohen, \& Cairns. (2012). Is searching for meaning in life associated with reduced subjective well-being? Confirmation and possible moderators. Journal of Happiness Studies, 13, 313-331.

Cohen, R., Bavishi, C., \& Rozanski, A. (2016). Purpose in life and its relationship to all-cause mortality and cardiovascular events: a meta-analysis. Psychosomatic medicine, 78, 122133.

Crumbaugh, J. C., \& Maholick, L. T. (1964). An experimental study in existentialism: The psychometric approach to Frankl's concept of noogenic neurosis. Journal of Clinical Psychology, 20(2), 200-207. doi:10.1002/1097-4679(196404)20:2

Cukur, C. S., De Guzman, M. R. T., \& Carlo, G. (2004). Religiosity, values, and horizontal and vertical individualism - Collectivism: A study of Turkey, the United States, and the Philippines. The Journal of Social Psychology, 144, 613-634.

Dagli, A. \& Baysal, N. (2016). Adaptation of the satisfaction with life scale into Turkish: the study of validity and reliability. Electronic Journal of Social Sciences, 15, 1250-1262.

Dezutter, J., Waterman, A. S., Schwartz, S. J., Luyckx, K., Beyers, W., Meca, A., . . Lee, R. M. (2014). Meaning in life in emerging adulthood: A person-oriented approach. Journal of personality, $82,57-68$.

Diener, E., Emmons, R. A., Larsen, R. J., \& Griffin, S. (1985). The satisfaction with life scale. Journal of Personality Assessment, 49, 71-75. 
Doğan, T., Sapmaz, F., Tel, F. D., Sapmaz, S., \& Temizel, S. (2012). Meaning in life and subjective well-being among Turkish university students. Procedia-Social and Behavioral Sciences, 55, 612-617.

Dogra, A. K., Basu, S., \& Das, S. (2008). The roles of personality, stressful life events, meaning in life, reasons for living on suicidal ideation: A study in college students. SIS Journal of Projective Psychology \& Mental Health, 15, 52.

Emmons, R.A.(2003).Personal goals,life meaning, and virtue: Wellsprings of a positive life. In C. Keyes, \&J. Haidt (Eds.), Flourishing: Positivepsychology and the life well-lived (pp. 105-128). Washington,DC: American Psychological Association.Fahlman, S. A., Mercer, K. B., Gaskovski, P., Eastwood, A. E., \& Eastwood, J. D. (2009). Does a lack of life meaning cause boredom? Results from psychometric, longitudinal, and experimental analyses. Journal of social and clinical psychology, 28, 307-340.

Fischer, I.C. (2019). Searching for Meaning in Life: The Moderating Roles of Hope and Optimism (Unpublished masters thesis). Indiana University Purdue University at Indianapolis, Indiana, USA.

Frankl, V. E. (1985). Man's search for meaning: Simon and Schuster.

George, L. S., \& Park, C. L. (2016). Meaning in life as comprehension, purpose, and mattering: Toward integration and new research questions. Review of General Psychology, 20, 205220.

George, L. S., \& Park, C. L. (2017). The multidimensional existential meaning scale: A tripartite approach to measuring meaning in life. The Journal of Positive Psychology, 12(6), 613627. 
Greenfield, P. M. (2014). Sociodemographic differences within countries produce variable cultural values. Journal of Cross-Cultural Psychology, 45(1), 37-41.

Gonzales, D. A., \& Jenkins, S. R. (2014). Cross-measure equivalence and communicability in the assessment of depression: a focus on factor-based scales. Assessment, 21, 731-741.

Hayes, A. F. (2013). Introduction to Mediation, Moderation, and Conditional Process Analysis: A Regression-Based Approach. New York, NY: The Guilford Press. Journal of Educational Measurement, 51, 335-337. Heidegger, M., Macquarrie, J., \& Robinson, E. (1962). Being and time. Malden, MA: Blackwell.

Heintzelman, S. J., \& King, L. A. (2014a). (The feeling of) meaning-as-information. Personality and Social Psychology Review, 18(2), 153-167.

Heintzelman, S. J., \& King, L. A. (2014b). Life is pretty meaningful. American Psychologist, 69(6), 561.

Ho, M. Y., Cheung, F. M., \& Cheung, S. F. (2010). The role of meaning in life and optimism in promoting well-beiin ng. Personality and individual differences, 48, 658-663.

Hofstede, G. (2001). Culture's consequences: Comparing values, behaviors, institutions and organizations across nations: Sage publications.

Hofstede Insights (n.d.) Country Comparision Tool. Retrieved from https://www.hofstedeinsights.com/ on May $4^{\text {th }} 2019$

House, R. J., Hanges, P. J., Javidan, M., Dorfman, P. W., \& Gupta, V. (Eds.). (2004). Culture, leadership, and organizations: The GLOBE study of 62 societies. Sage publications.

Imamoglu, E. O., \& Imamoglu, V. (1992). Life situations and attitudes of the Turkish elderly toward institutional living within a cross-cultural perspective. Journal of Gerontology: Psychological Sciences, 47, 102-108. doi:10.1093/geronj/47.2.P102 
Imamoglu, E. O., Kuller, R., Imamoglu, V., \& Kuller, M. (1993). The social psychological worlds of Swedes and Turks in and around retirement. Journal of Cross-Cultural Psychology, 24(1), 26-41. doi:10.1177/0022022193241002

Juhl, J., \& Routledge, C. (2016). Putting the terror in terror management theory: evidence that the awareness of death does cause anxiety and undermine psychological well-being. Current Directions in Psychological Science, 25, 99-103.

Kagitcibasi, C. (2005). Autonomy and relatedness in cultural context: Implications for self and family. Journal of cross-cultural psychology, 36, 403-422.

Kapci, E. G., Uslu, R., Turkcapar, H., \& Karaoglan, A. (2008). Beck Depression Inventory II: evaluation of the psychometric properties and cut-off points in a Turkish adult population. Depression and Anxiety, 25, E104-E110.

Karakitapoĝlu-Aygün, Z., \& Imamoĝlu, E. O. (2002). Value domains of Turkish adults and university students. The Journal of Social Psychology, 142, 333-351.

Kemer, G. (2006). The role of self-efficacy, hope, and anxiety in predicting university entrance examination scores of eleventh-grade students. Unpublished master thesis, Middle East Technical University, Ankara.

Kern, M.L., Waters, L.E., Adler, A., \& White, M.A. (2015) A multidimensional approach to measuring well-being in students: Application of the PERMA framework. The Journal of Positive Psychology, 10(3), 262-271. doi: 10.1080/17439760.2014.936962

Kierkegaard, S., Swenson, D. F., Swenson, L. M., \& Lowrie, W. (1946). Either/or: A fragment of life. Princeton, NJ, US: Princeton University Press

Kleftaras, G., \& Psarra, E. (2012). Meaning in life, psychological well-being and depressive symptomatology: A comparative study. Psychology, 3, 337-345. 
Klinger, E. (1977). Meaning and void: Inner experience and the incentives in peoples lives. Minneapolis, MN: University of Minnesota Press.

Köker, S. (1991). Comparison of the level of life satisfaction of normal adolescents and adolescents with problems. Unpublished Master Thesis, the Institute of Social Sciences, Ankara University, Ankara.

Koltko-Rivera, M. E. (2004). The psychology of worldviews. Review of General Psychology, 8, $3-58$.

Krause, N. (2007). Longitudinal study of social support and meaning in life. Psychology and aging, 22, 456-469.

Krause, N., \& Hayward, R. D. (2014). Assessing stability and change in a second-order confirmatory factor model of meaning in life. Journal of happiness studies, 15(2), 237253.

Krok, D. (2014). The religious meaning system and subjective well-being: The mediational perspective of meaning in life. Archive for the Psychology of Religion, 36(2), 253-273.

Krok, D. (2015). The role of meaning in life within the relations of religious coping and psychological well-being. Journal of Religion and Health, 54(6), 2292-2308.

Markus, H. R., \& Kitayama, S. (1991). Culture and the self: Implications for cognition, emotion, and motivation. Psychological review, 98, 224-253.

Martela, F., \& Steger, M. F. (2016). The three meanings of meaning in life: Distinguishing coherence, purpose, and significance. The Journal of Positive Psychology, 11, 531-545.

McKnight, P. E., \& Kashdan, T. B. (2009). Purpose in life as a system that creates and sustains health and well-being: An integrative, testable theory. Review of General Psychology, 13(3), 242-251. 
Öner, N., \& Le Compte, A. (1983). Handbook of state-trait anxiety. Istanbul, Turkey, Bogazici University Publication.

Pan, J.-Y., Wong, D. F. K., Joubert, L., \& Chan, C. L. W. (2008). The protective function of meaning of life on life satisfaction among Chinese students in Australia and Hong Kong: A cross-cultural comparative study. Journal of American College Health, 57, 221-232.

Park, N., Park, M., \& Peterson, C. (2010). When is the search for meaning related to life satisfaction? Applied Psychology: Health and Well-Being, 2, 1-13.

Peterson, C., Park, N., \& Seligman, M. E. (2005). Orientations to happiness and life satisfaction: The full life versus the empty life. Journal of Happiness Studies, 6, 25-41.

Pinquart, M. (2002). Creating and maintaining purpose in life in old age: A meta-analysis. Ageing international, 27, 90-114.

Radloff, L. S. (1977). The CES-D scale: A self-report depression scale for research in the general population. Applied psychological measurement, 1, 385-401.

Reker, G. T., \& Peacock, E. J. (1981). The Life Attitude Profile (LAP): A multidimensional instrument for assessing attitudes toward life. Canadian Journal of Behavioural Science/Revue Canadienne Des Sciences Du Comportement, 13(3), 264-273. Doi:10.1037/h0081178

Reker, G.T.,\&Woo,L.C.(2011).Personal meaning orientations and psychosocial adaptation in older adults. SAGE Open,1-11 Schnell, T. (2010). Existential indifference: Another quality of meaning in life. Journal of Humanistic Psychology, 50(3), 351-373. 
Schnell, T. (2009). The Sources of Meaning and Meaning in Life Questionnaire (SoMe): Relations to demographics and well-being. The Journal of Positive Psychology, 4(6), 483-499.

Schnell, T. (2010). Existential indifference: Another quality of meaning in life. Journal of Humanistic Psychology, 50(3), 351-373.

Schnell, T.(2011). Individual differences in meaning-making: Considering the variety of sources of meaning, their density and diversity. Personality and Individual Differences,51, 667673.

Schnetzer, L. W., Schulenberg, S. E., \& Buchanan, E. M. (2013). Differential associations among alcohol use, depression and perceived life meaning in male and female college students. Journal of Substance Use, 18, 311-319.

Shean, G., \& Baldwin, G. (2008). Sensitivity and specificity of depression questionnaires in a college-age sample. The Journal of genetic psychology, 169, 281-292.

Singelis, T. M., Triandis, H. C., Bhawuk, D. P., \& Gelfand, M. J. (1995). Horizontal and vertical dimensions of individualism and collectivism: A theoretical and measurement refinement. Cross-cultural research, 29, 240-275.

Singh, K., Junnarkar, M., Jaswal, S., \& Kaur, J. (2016). Validation of Meaning in Life Questionnaire in Hindi (MLQ-H). Mental Health, Religion \& Culture, 19, 448-458.

Spielberger, C. D., Gorsuch, R. L., Lushene, R., Vagg, P., \& Jacobs, G. (1983). Consulting Psychologists Press; Palo Alto, CA: 1983. Manual for the state-trait anxiety inventory.

Steger, M. F. (2012). Experiencing meaning in life: Optimal functioning at the nexus of spirituality, psychopathology, and well-being. In P. T. P. Wong (Eds.), The human quest 
for meaning: Theories, research, and applications (2nd ed., pp. 165-184). New York, NY: Routledge/Taylor \& Francis Group.

Steger, M. F., Frazier, P., Oishi, S., \& Kaler, M. (2006). The meaning in life questionnaire: Assessing the presence of and search for meaning in life. Journal of counseling psychology, 53, 80-93.

Steger, M. F., Kashdan, T. B., Sullivan, B. A., \& Lorentz, D. (2008). Understanding the search for meaning in life: Personality, cognitive style, and the dynamic between seeking and experiencing meaning. Journal of personality, 76, 199-228.

Steger, M. F., Kawabata, Y., Shimai, S., \& Otake, K. (2008). The meaningful life in Japan and the United States: Levels and correlates of meaning in life. Journal of Research in Personality, 42, 660-678.

Steger, M. F., Mann, J. R., Michels, P., \& Cooper, T. C. (2009). Meaning in life, anxiety, depression, and general health among smoking cessation patients. Journal of Psychosomatic Research, 67, 353-358.

Steger, M. F., Oishi, S., \& Kashdan, T. B. (2009). Meaning in life across the life span: Levels and correlates of meaning in life from emerging adulthood to older adulthood. The Journal of Positive Psychology, 4, 43-52.

Steger, M. F., Oishi, S., \& Kesebir, S. (2011). Is a life without meaning satisfying? The moderating role of the search for meaning in satisfaction with life judgments. The Journal of Positive Psychology, 6, 173-180.

Tillich, P. (2000). The Courage to Be: Second Edition. New Haven, CT: Yale University Press 
Triandis, H. C., \& Gelfand, M. J. (1998). Converging measurement of horizontal and vertical individualism and collectivism. Journal of personality and social psychology, 74, 118128.

Tukey, J. W. (1962). The future of data analysis. The annals of mathematical statistics, 33, 1-67.

Türküm, S. (2001). Stresle başa çıkma biçimi, iyimserlik, bilişsel çarpıtma düzeyleri ve psikolojik yardım almaya ilişkin tutumlar arasındaki ilişkiler: Üniversite öğrencileri üzerinde bir araştırma.

Uz, I. (2015). The index of cultural tightness and looseness among 68 countries. Journal of Cross-Cultural Psychology, 46(3), 319-335.

Wang, M.-C., \& Dai, X.-Y. (2008). Chinese Meaning in Life Questionnaire Revised in College students and its reliability and validity test. Chinese Journal of Clinical Psychology, 16, $459-461$.

Watson, D., Clark, L. A., \& Tellegen, A. (1988). Development and validation of brief measures of positive and negative affect: The PANAS scales. Journal of Personality and Social Psychology, 54(6), 1063-1070. doi:10.1037/0022-3514.54.6.106

Wong, P. T. P. (2012). Toward a dual-systems model of what makes life worth living. In P. T. P. Wong (Ed.), Personality and clinical psychology series. The human quest for meaning: Theories, research, and applications (pp. 3-22). New York, NY, US: Routledge/Taylor \& Francis Group.

Winger, J. G., Adams, R. N., \& Mosher, C. E. (2016). Relations of meaning in life and sense of coherence to distress in cancer patients: A meta-analysis. Psycho-Oncology, 25(1), 2-10.

Yalom, I. D. (1980). Existential psychotherapy (Vol. 1). New York: Basic Books. 
Table 1

Bivariate correlations between study variables in the US $(N=361)$ and Turkey $(N=202)$

\begin{tabular}{lccccccc}
\hline USA & 1 & 2 & 3 & 4 & Mean & SD & $\alpha$ \\
\hline 1. Presence of meaning & - & & & & 23.71 & 6.62 & .87 \\
2. Search for meaning & $-.14 *$ & - & & & 24.92 & 6.94 & .90 \\
3. Satisfaction with life & $.56 * * *$ & -.08 & - & & 23.38 & 5.93 & .86 \\
4. Anxiety & $-.47 * * *$ & $.11 *$ & $-.47 * * *$ & - & 41.11 & 13.05 & .94 \\
5. Depression (BDI) & $-.47 * * *$ & $.12 *$ & $-.49 * * *$ & $.71 * * *$ & 12.80 & 7.66 & .91 \\
& & & & & & & \\
Turkey & 6 & 7 & 8 & 9 & Mean & SD & $\alpha$ \\
\hline 6. Presence of meaning & - & & & & 23.32 & 6.48 & .90 \\
7. Search for meaning & $-.20^{* *}$ & - & & & 25.05 & 5.93 & .88 \\
8. Satisfaction with life & $.50 * * *$ & $-.30^{* * *}$ & - & & 23.75 & 5.77 & .83 \\
9. Anxiety & $-.45 * * *$ & $.21 * *$ & $-.41 * * *$ & - & 41.38 & 10.33 & .94 \\
10. Depression (BDI) & $-.54 * * *$ & $.25 * * *$ & $-.56 * * *$ & $.71 * * *$ & 12.30 & 8.20 & .87 \\
\hline
\end{tabular}

Note: ${ }^{\dagger}$ BDI-II equivalents of the CES-D scale scores are used in the analyses. Mean and standard deviation of the transformed scores are reported. Cronbach's alpha is computed based on the CES-D scores.

$\stackrel{*}{p}<.05 ;{ }^{* *} p<.01 ;{ }^{* * *} p<.001$

Zika, S., \& Chamberlain, K. (1992). On the relation between meaning in life and psychological well-being. British journal of psychology, 83, 133-145. 


\section{Table 2}

Moderation by culture of the relationships between search for meaning and psychological wellbeing outcomes

\begin{tabular}{|c|c|c|c|c|c|c|}
\hline 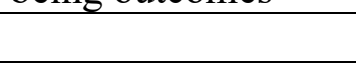 & $b$ & SE & $R^{2}$ & $d f$ & $F$ & $p$ \\
\hline \multicolumn{7}{|c|}{ DV: Satisfaction with life } \\
\hline Stepl & & & .048 & 4 & 6.907 & $<.001$ \\
\hline Intercept & 25.90 & 1.97 & & & & $<.001$ \\
\hline Gender & 1.23 & .34 & & & & $<.001$ \\
\hline Age & .03 & .08 & & & & .715 \\
\hline Culture & -.26 & .26 & & & & .314 \\
\hline Search for meaning & -.15 & .04 & & & & $<.001$ \\
\hline Step 2 & & & .060 & 5 & 7.066 & $<.001$ \\
\hline Search X Culture & .11 & .04 & & & & .007 \\
\hline \multicolumn{7}{|c|}{ DV: Depressive symptoms } \\
\hline Stepl & & & .036 & 4 & 5.151 & .001 \\
\hline Intercept & 11.52 & 2.65 & & & & $<.001$ \\
\hline Gender & .51 & .46 & & & & .275 \\
\hline Age & -.20 & .11 & & & & .070 \\
\hline Culture & .09 & .35 & & & & .796 \\
\hline Search for meaning & .19 & .05 & & & & $<.001$ \\
\hline Step 2 & & & .043 & 5 & 4.858 & $<.001$ \\
\hline Search X Culture & -.11 & 06 & & & & .059 \\
\hline \multicolumn{7}{|c|}{ DV: Anxiety symptoms } \\
\hline Stepl & & & .027 & 4 & 3.836 & .004 \\
\hline Intercept & 40.23 & 4.11 & & & & $<.001$ \\
\hline Gender & .53 & .71 & & & & .426 \\
\hline Age & -.29 & .17 & & & & .458 \\
\hline Culture & -.36 & .54 & & & & .507 \\
\hline Search for meaning & .26 & .08 & & & & .001 \\
\hline Step 2 & & & .022 & 5 & 3.219 & .007 \\
\hline Search X Culture & -.08 & .09 & & & & .358 \\
\hline
\end{tabular}


Table 3

Interaction between search for meaning, presence of meaning, and culture

\begin{tabular}{|c|c|c|c|c|c|c|}
\hline & $b$ & SE & $R^{2}$ & $d f$ & $F$ & $p$ \\
\hline \multicolumn{7}{|l|}{ DV: Depressive symptoms } \\
\hline Step 1 & & & .26 & 5 & 39.09 & $<.001$ \\
\hline Intercept & 26.07 & 2.58 & & & & $<.001$ \\
\hline Gender & .72 & .41 & & & & .077 \\
\hline Age & -.13 & .10 & & & & .175 \\
\hline Culture & .26 & .31 & & & & .401 \\
\hline Presence of meaning & -.58 & .05 & & & & $<.001$ \\
\hline Search for meaning & .09 & .05 & & & & .041 \\
\hline Step 2 & & & .26 & 9 & 23.02 & $<.001$ \\
\hline Search X Presence & -.01 & .01 & & & & .255 \\
\hline Presence X Culture & -.34 & .17 & & & & .042 \\
\hline Search X Culture & -.45 & .17 & & & & .006 \\
\hline Search X Presence X Culture & .02 & .01 & & & & .015 \\
\hline \multicolumn{7}{|l|}{ DV: Anxiety symptoms } \\
\hline Step 1 & & & .22 & 5 & 30.50 & $<.001$ \\
\hline Intercept & 60.79 & 4.10 & & & & $<.001$ \\
\hline Gender & .78 & .64 & & & & .223 \\
\hline Age & -.19 & .16 & & & & .231 \\
\hline Culture & -.14 & .49 & & & & .781 \\
\hline Presence of meaning & -.82 & .07 & & & & $<.001$ \\
\hline Search for meaning & .12 & .07 & & & & .102 \\
\hline Step 2 & & & .24 & 9 & 18.66 & $<.001$ \\
\hline Search X Presence & -.01 & .01 & & & & .501 \\
\hline Presence X Culture & -.91 & .26 & & & & $<.001$ \\
\hline Search X Culture & -.84 & .26 & & & & .001 \\
\hline Search X Presence X Culture & .03 & .01 & & & & .002 \\
\hline
\end{tabular}




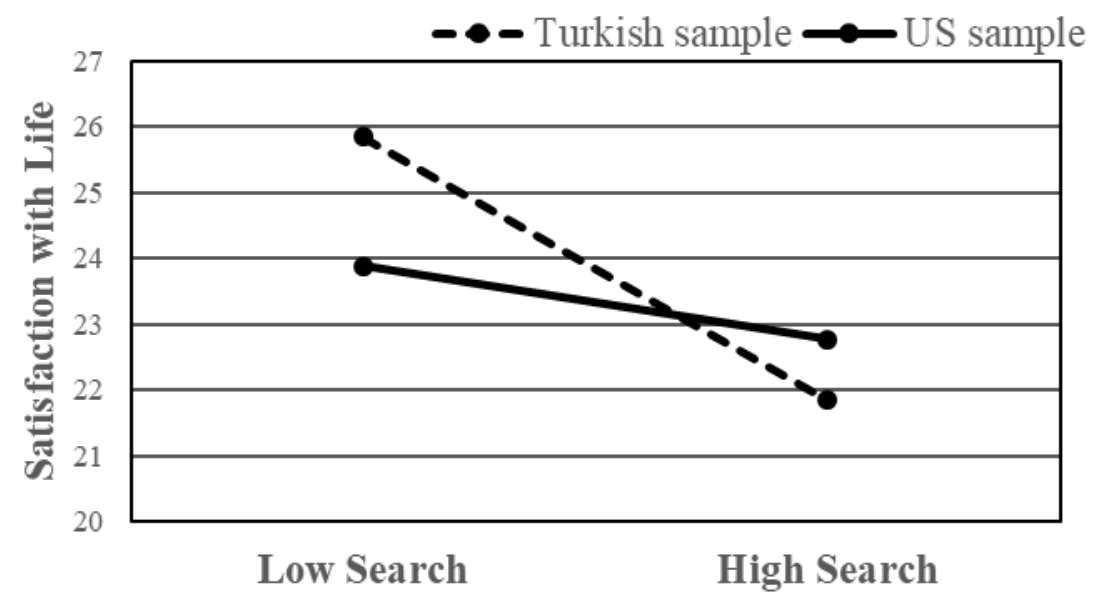

Figure 1.

The interaction between search for meaning and culture predicting satisfaction with life. 
A.

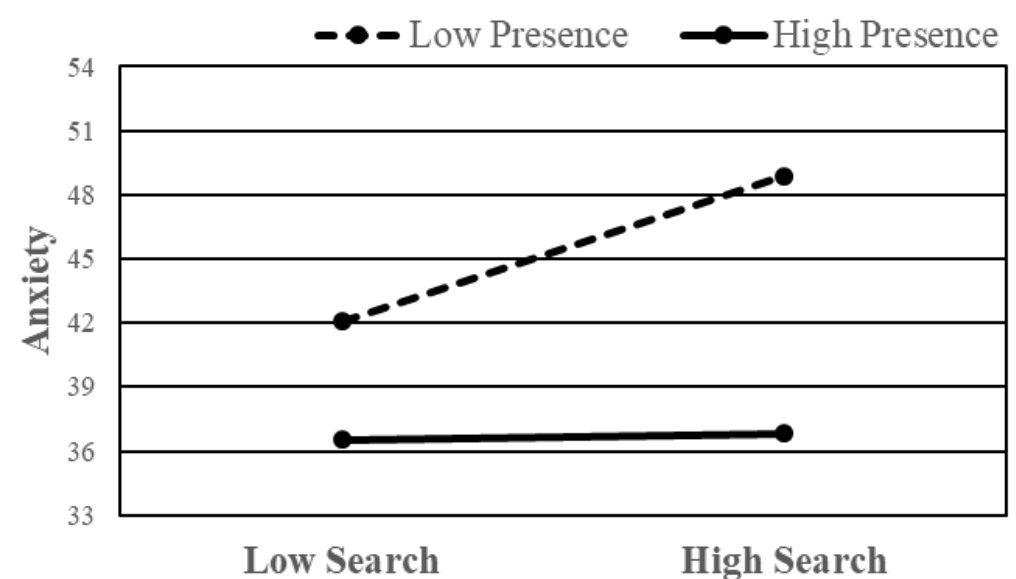

C.

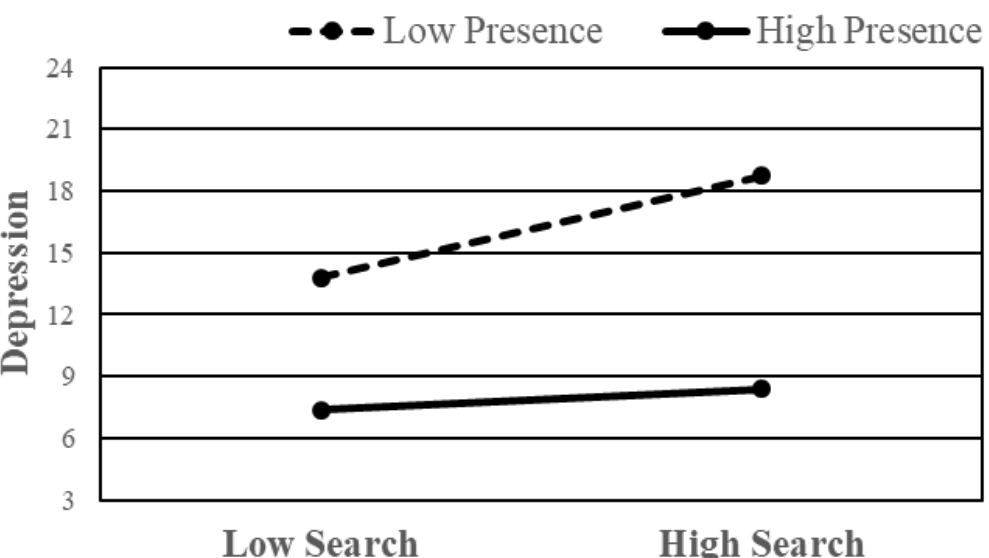

B.

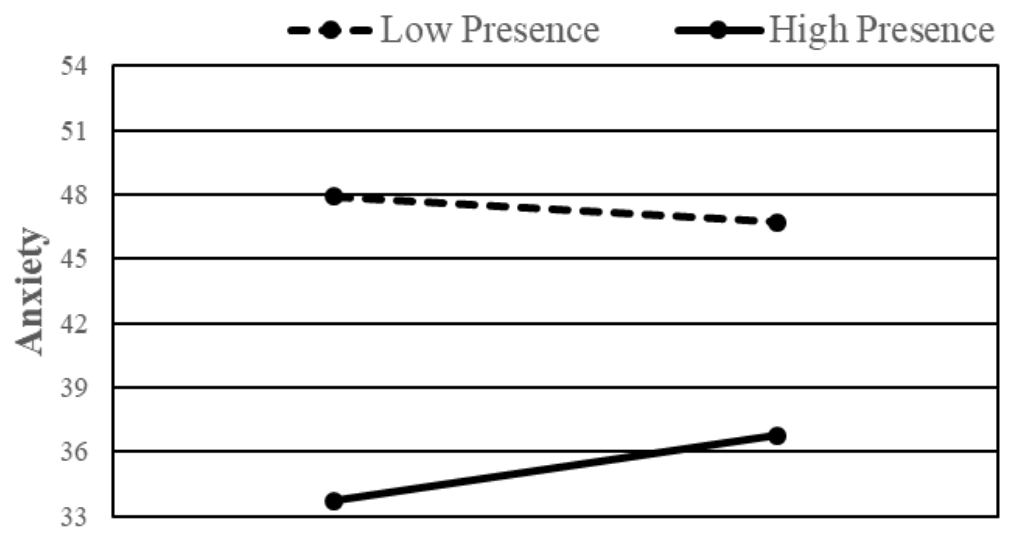

Low Search

High Search

D.

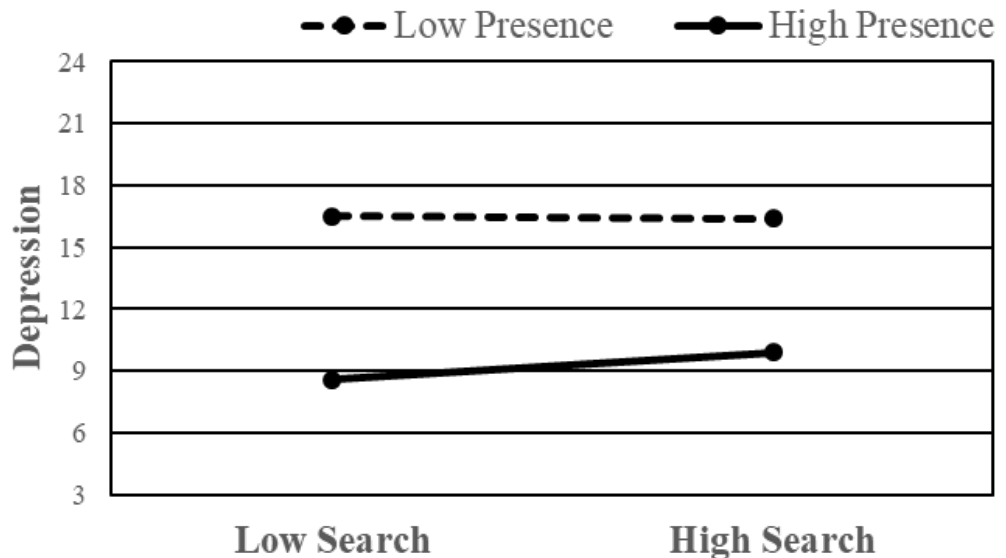

A. Interaction of presence and search for meaning predicting depressive symptoms in the Turkish sample. B. Interaction of presence and search for meaning predicting depressive symptoms in the US sample. C. Interaction of presence and search for meaning predicting anxiety symptoms in the Turkish sample. D. Interaction of presence and search for meaning predicting anxiety symptoms in the US sample. 